\section{Editorial: A RECADM no Redalyc e o Dilema das Bases e Indexadores}

Próximo ao feriado de Páscoa, a Boa Nova desta edição é a felicidade que tivemos com a aceitação, por unanimidade, da RECADM pela base Redalyc - Rede de Revistas Científicas da América Latina, Caribe, Espanha e Portugal. Nas próprias palavras da Rede, o Redalyc "é um projeto acadêmico para a difusão em acesso aberto da atividade editorial científica que ocorre na e sobre a Ibero-América. [...] Promovido pela Universidade Autônoma do Estado do México (em colaboração com centenas de instituições de ensino superior, centros de pesquisa, associações profissionais e editoras ibero-americanas), surge em 2003 como uma iniciativa de um grupo de pesquisadores e editores preocupados com a baixa visibilidade dos resultados de pesquisa gerados na e sobre a região. Desde a sua criação, propôs-se ser um ponto de encontro para os interessados em reconstruir o conhecimento científico da Ibero-América".

Nosso interesse em fazer parte desta base vai além da vantagem instrumental que ela nos dá, já que ser indexado pela Redalyc é um dos critérios de diferenciação dos periódicos no Qualis da Área de Administração, Contabilidade e Turismo. Mas, também, porque muitos dos princípios que guiaram a constituição da Rede Redalyc, como a valorização do acesso aberto, das ciências sociais e humanidades e do conhecimento iberoamericano, são muito próximos daqueles compartilhados pela RECADM e por sua mantenedora, o Instituto Brasileiro de Estudos e Pesquisas Sociais - IBEPES. Ao ponto que muitos desses princípios já foram declarados em outras iniciativas também desenvolvidas pelos membros do IBEPES, em especial, o Spell, que é a base dedicada aos periódicos brasileiros da área de administração, contabilidade e turismo. Somada a tal afinidade de princípios, fazer parte do Redalyc pode proporcionar à RECADM maior número de acessos e leitores nos demais países da América Latina e Península lbérica, público que ainda temos pouco alcance.

Assim, nada mais natural que ficássemos felizes e satisfeitos em fazer parte de uma base de periódicos que é coerente com a nossa filosofia e, ao mesmo tempo, instrumentalmente válida. No entanto, todos nós sabemos que a estratégia de ciência aberta e gratuita que adotamos no Brasil necessita de um grande empenho de instituições de ensino e pesquisa e de suporte tecnológico das bibliotecas institucionais para operacionalizar as plataformas OJS, que nem sempre funcionam a contento. Mais ainda, nosso formato, apesar de ser o mais socialmente justo, por ser aberto e gratuito para usuários e autores, ao meu ver, exige um esforço e dedicação imensos de editores e equipe editorial, já que eles têm que lidar, ao mesmo tempo, com demandas de apreciação científica e trabalho operacional de organização editorial. Então, fica a pergunta: realmente vale a pena despender ainda mais tempo, e até dinheiro, para atender mais demandas oriundas de bases e indexadores no já atribulado trabalho voluntário da equipe editorial?

No caso da Redalyc, que era algo que nós almejávamos, creio que sim. Mas nas tantas outras bases e indexadores que recorrentemente
Luciano Rossoni (iD,

Editor da RECADM

UniGranRio, Brasil

Irossoni@gmail.com 
solicitam formulários e envio de dados, me questiono qual a necessidade de se fazer parte e, mais ainda, de dispor de horas de trabalho para ajustar o nosso portal, bem como em atender aos critérios. Olhando para a própria RECADM, de que eu tenha conhecimento, fazemos parte de um total de 60 bases e indexadores. Algumas delas operam quase que automaticamente, não havendo muito custo em se manter. Mas algumas outras solicitam correntemente o preenchimento de formulários imbricados e a submissão de artigos, edições e informações em formatos muitas vezes exotéricos para leigos como eu no processo de indexação editorial. E toda vez que há o engajamento em atender tais exigências, eu sempre me questiono: para que fazer isso? Para que atender e participar de tantas bases e indexadores se, na maioria delas, não há qualquer evidência de algum tipo de retorno em termos de visibilidade e acesso, muito menos da certeza de como nossos dados e pesquisas são tratadas?

Tenho convicção de que os demais editores, assim como eu, recorrentemente tendem a aquiescer ao convite de participar de um número cada vez maior de bases devido a crença de que mais é melhor. A incorporação de tal pressuposto nos leva a aceitar a participação, especialmente quando gratuita, sem considerar os custos e ônus. No entanto, diante do número cada vez maior de bases e indexadores sedentos por acessar gratuitamente o fruto de nosso trabalho científico, entendo que precisamos ser cada vez mais seletivos em tais aceites.

Tal discussão sobre a utilidade e sobre os critérios de aceite de participar das bases e indexadores devem ser amadurecidos na nossa comunidade. Temos algo que é muito valioso, que é o conhecimento gerado por pesquisadores, estudantes e instituições de ensino públicas e privadas, muitas delas bancadas com o suor do já sofrido contribuinte, para simplesmente entregar sem barganha às entidades e companhias que têm interesse meramente comercial. Sendo assim, eu entendo que os periódicos e seus editores devam fazer alguns julgamentos sobre a participação em tais bases.

O primeiro deles, puramente instrumental, e mais simples de todos, é questionar até que ponto participar de uma base em particular dá algum retorno em visibilidade e prestígio para o periódico. De todas as bases disponíveis, eu me questiono se os usuários buscam acesso recorrente em mais do que três, e duvido ainda de que a imensa maioria já visitou e fez buscas em mais de dez bases diferentes. Logo, os editores precisam questionar a real utilidade de se autorizar o uso comercial de nossas pesquisas por bases com efetividade duvidosa.

O segundo deles remete a uma questão de justiça com quem efetivamente faz pesquisa e a sustenta nesse país. Se nossos periódicos possuem acesso gratuito, não cobram dos autores para publicarem, só existem devido ao empenho de professores e pesquisadores, que em muitos casos são financiados com recursos públicos, por que nós deveríamos autorizar que bases e indexadores explorem nossos dados e artigos de forma comercial? Vejo muito contrassenso de nossa parte em aceitar facilmente que algumas bases explorem o que produzimos como desejam. Algumas delas deixam claro que farão exploração comercial e, inclusive, remuneram os periódicos pelo ganho que obtêm. Mas algumas, além de usarem os 
periódicos de forma comercial, nem sequer permitem que o periódico tenha acesso aos próprios dados, pois são de conteúdo fechado. Tal situação é, no mínimo, absurda. Em alguns casos, há outros interesses subjacentes à participação, como participar do Web of Science, cuja grande visibilidade e prestígio trazem muitos ganhos para o periódico. Logo, independentemente de se concordar com o ônus da participação, os periódicos aderem pelas vantagens. Entretanto, em alguns casos, tais bases faturam alto nesse mercado sem qualquer contrapartida para o periódico.

Por fim, entendo que os periódicos devam também julgar se os princípios que norteiam tais bases estão de acordo com os seus princípios e os da mantenedora. Isso porque a partir do momento que os usuários têm acesso ao periódico por meio de uma base, em especial quando a origem do periódico é desconhecida para eles, a tendência é de que eles atribuam toda a lógica de funcionamento e filosofia da base e do indexador ao periódico. Nos casos com intuito de exploração comercial, tais contradições tendem a ser menores. Já no caso dos periódicos nacionais, por sermos adeptos do sistema de acesso livre e gratuito ao conteúdo, sem uso comercial, as contradições tendem a ser maiores. E, mesmo que não seja evidente para os periódicos e editores nacionais, existe a responsabilidade de cada um que faz parte de tal sistema zelar pelo princípio de conhecimento livre, aberto e gratuitamente acessível.

Por essas razões, eu apelo aos editores para que reflitam sobre o dilema entre aceitar ou não a participação em algumas bases, pois os periódicos de áreas e de países intitulados por alguns como "periféricos" também têm a capacidade de moldar o campo para algo mais justo e igualitário, especialmente quando operamos em imensa desvantagem comparados aos periódicos de editoras comerciais.

\section{Nesta edição}

Nossa segunda edição de 2019 apresenta artigos que lidam com áreas como consumo e mercado, trabalho, empreendedorismo e pequenas empresas. Acerca da primeira área, e remetendo ao consumo propriamente dito, Flávia Zimmerle da Nóbrega Costa e André Luiz Maranhão de Souza-Leão discutem no artigo "A vontade de potência do prossumidor: uma análise da vontade e da força da vontade nas práticas dos potterheads", como o consumo dos potterheads se caracteriza em relação à sua vontade de potência. Para tanto, os autores assumem que potterheads são consumidores produtivos. Por essa razão, tomaram o pensamento deleuziano para compreender como a vontade de potência, um conceito central no trabalho, é uma força operada relacionalmente entre afeto e memória. Os autores adotaram a Análise de Discurso Foucaultiana, com base em um arquivo de dados documentais coletados em mídias digitais. Os achados apontam para uma formação discursiva referente a como a vontade de potência dos potterheads oscila de acordo com a ambivalências das emoções positivas e negativas, que se expressam por meio de ideias postas em evidência no decorrer de encontros com demais prossumidores. 
O segundo artigo, "Efeitos das Mídias Digitais nas Novas Vendas B2B: Um ensaio sobre inbound marketing, mídias pagas e ganhadas on-line", dos autores Nôga Simões de Arruda Corrêa da Silva e Valter Afonso Vieira, sugere um modelo teórico em que o inbound marketing, as mídias pagas e as mídias ganhadas on-line possuem efeitos no desempenho das novas vendas B2B. As proposições desenvolvidas no ensaio apontaram que o inbound marketing pode ser a mídia mais proeminente no resultado de novas vendas B2B, sendo que as mídias pagas e ganhadas on-line podem exercer influência direta no mesmo e indireta nas vendas. Além disso, os autores sugerem quadros explicativos e informativos dos resultados anteriores do inbound marketing, das mídias pagas e das mídias ganhadas on-line, bem como apontam caminhos para futuras pesquisas.

No terceiro artigo, a questão do trabalho ascende, em que Ana Virgínia Alberici Giordani Bertolini e Fabiano Larentis analisam, no artigo "Expatriação e Processos de Aprendizagem Organizacional: um estudo de casos múltiplos", a contribuição da expatriação para os processos de aprendizagem organizacional. Por meio de um estudo de casos múltiplos, os autores observaram que a expatriação tende a desencadear processos de aprendizagem organizacional que se encontram embutidos nas atividades cotidianas do indivíduo. Apontam também que os empregados aprenderam, a partir de suas experiências, a enfrentar um problema ou desafio por meio da reflexão, interação e colaboração com colegas. Além disso, o expatriado enxerga a sua própria cultura sob uma nova ótica, toma conhecimento de outras culturas organizacionais e identifica novas formas de lidar com pessoas.

O quarto artigo, "Bem-Estar Subjetivo de Imigrantes Senegaleses", que também lida com o trabalho, mais especificamente, com o trabalhador estrangeiro, de autoria de Jaqueline de Quadros Dill Lague, Shalimar Gallon e Priscila Sardi Cerutti, teve como objetivo descrever o bem-estar subjetivo de imigrantes senegaleses por meio de uma pesquisa qualitativa baseada em um grupo focal com tais imigrantes e em entrevistas semiestruturadas com gestores. Os resultados indicam que as categorias que afetam no sentimento de bem-estar dos imigrantes senegaleses são elementos econômicos e culturais, expectativas e emoções. Estes resultados demonstram como ocorre a relação entre o trabalhador imigrante e a empresa em que ele está inserido.

Já no quinto artigo, "Motivadores da Internacionalização de Pequenas Empresas de Software: um estudo multi casos nos contextos brasileiro e espanhol", asautoras AlessandraHerranzGazquezeHilkaPelizzaVierMachado buscaram conhecer os motivadores da internacionalização de pequenas empresas do setor de software. Por meio de um estudo múltiplo de casos, realizado junto a cinco pequenas empresas de software em dois contextos, no Estado do Paraná, e em Valência, Espanha, as autoras identificaram seis motivadores de internacionalização: 1) a competição; 2) busca por novos mercados; 3) colocação de produto inovador; 4) oportunidade casual; 5) crescimento; 6) acesso a mercados internacionais para buscar recursos humanos. A contribuição do estudo foi analisar a internacionalização de pequenas empresas em dois contextos, propiciando maior abrangência 
nas conclusões sobre motivadores de internacionalização, cujos resultados podem ser úteis às empresas de software que desejam se internacionalizar, de modo a se espelharem nos motivadores mencionados.

Por fim, no sexto artigo, "Autodeterminação e Empreendedorismo com Suporte em Motivações: análise empírica com universitários do curso de administração", as autoras Fabiana Pinto de Almeida Bizarria, Flávia Lorenne Sampaio Barbosa e Antônia Márcia Rodrigues Sousa investigaram a influência da motivação acadêmica na motivação empreendedora. Por meio de um levantamento com 245 universitários de administração de sete instituições de ensino superior nordestinas, os resultados apontaram relações positivas entre desmotivação acadêmica, regulação externa e regulação introjetada na motivação empreendedora. Acredita-se que o estudo potencialmente avance no sentido de considerar que o aprendizado não supre as reais expectativas e motivações dos acadêmicos para empreender. Para tanto, sugere-se que cursos e programas, que visem a formação empreendedora, conduzam seus objetivos de forma a moldar-se às motivações prévias dos alunos, a fim de obter maior eficácia pedagógica.

Para finalizar, queria destacar algumas ferramentas que foram implementadas no portal da RECADM no início deste ano de 2019. Uma delas é a aba Estatísticas, que apresenta, em tempo real, dados de acesso ao periódico desde o final de dezembro de 2018. Os leitores podem visualizar o número de acessos e downloads mensalmente ou anualmente, bem como de quais países partem tais acessos. É possível também identificar quais artigos são mais baixados, quais são mais acessados e o número de acessos por edição. Para aqueles que são orientadores de TCC de graduação, verão uma forte relação com os temas mais escolhidos entre os alunos e o número de acessos e downloads dos artigos.

Outra ferramenta bem interessante que incorporamos na RECADM, que opera no nível dos artigos, é a PlumX Metrics: https://plumanalytics.com/learn/ about-metrics/. Tais métricas têm como objetivo mostrar como pesquisadores e usuários interagem com os artigos, indo além das estatísticas de acessos, downloads e citações. Como visto na figura ao lado, o PlumX exibe a frequência relativa de tais interações por meio de círculos que compõem uma figura com cinco eixos, cada uma representando uma categoria distinta: 1) citações (círculo vermelho), cujas fontes são, por exemplo, o SCOPUS e o Crossref; 2) Uso (círculo verde), que contabiliza visualizações do texto completo, dos resumos e de quando seus links são compartilhados; 3) Capturas (círculo roxo), quando metadados, referências e demais informações são captadas por meio de aplicativos como Mendeley; 4) Menções (ausente na figura, mas de cor amarela), quando há comentários e apontamentos em blogs e em fóruns de discussão; 5) Mídia Social (círculo azul claro), que contabiliza menções em redes sociais como Twitter e Facebook.

O PlumX e outras ferramentas como, por exemplo, o Altmetrics, são uma tentativa de captar o impacto de periódicos indo além das citações, algo que vem sendo legitimado pelo cada vez mais eloquente discurso do impacto da pesquisa. Todavia, sua operacionalização foi fortemente influenciada por evidências de que existe alguma relação entre menções no Twitter dirigidas a

\begin{tabular}{|l|}
\hline CPLUMX \\
\hline Citations \\
Citation Indexes: 6 \\
\hline $\begin{array}{l}\text { Usage } \\
\text { Full Text Views: } 46 \\
\text { Abstract Views: } 32 \\
\text { Link-outs: } 6\end{array}$ \\
\hline $\begin{array}{l}\text { Captures } \\
\text { Exports-Saves: } \mathbf{5} \\
\text { Readers: } \mathbf{1 8}\end{array}$ \\
\hline Social Media \\
\hline Tweets: $\mathbf{1}$ \\
\hline
\end{tabular}


um artigo com futuras citações (Eysenbach, 2011). Daí a ênfase em capturar menções em redes sociais e na internet. Não dá para se atribuir algum tipo de causalidade em tais estudos, especialmente considerando mídias sociais, que muitas vezes correm a parte do contexto do pesquisador brasileiro. Mas, de qualquer forma, é uma interessante forma de se antever a atenção dada pelo público em geral aos artigos.

Devo destacar que o PlumX ainda apresenta problemas de natureza operacional que limitam seu uso. Por exemplo, as menções no Facebook ainda não são devidamente recuperadas. Algo que a equipe do PlumX tem ciência, mas ainda não deu conta de revisar. Já as demais métricas, como compartilhamentos no Twitter e capturas no Mendeley, operam de forma quase que instantânea. Diante dessas limitações, entendo que cabe a nós pesquisadores muito mais usufruir das vantagens de tais ferramentas do que acreditar em sua eficácia de avaliação. O que de forma alguma as invalida, mas que nos alerta em ter cautela em fazer qualquer estrapolação.

Despeço-me mais uma vez agradecendo o generoso trabalho dos avaliadores, bem como da equipe que dá suporte à RECADM, que permite que eu me dedique cada vez mais ao conteúdo dos artigos e menos às questões técnicas e operacionais.

Uma excelente e prazerosa leitura,

\section{Luciano Rossoni}

Editor da RECADM

\section{Referências}

Eysenbach, G. (2011). Can tweets predict citations? Metrics of social impact based on Twitter and correlation with traditional metrics of scientific impact. Journal of Medical Internet Research, 13(4), e123. 